\title{
Evaluation of an Amharic-Language translation of Continuity of Care Satisfaction Tool among Postnatal Mothers in Ethiopia
}

Solomon Hailemeskel ( $\sim$ solomonhailemeskel9@gmail.com )

School of Midwifery, College of Medicine and Health Science, University of Gondar, Gondar, Ethiopia

Kassahun Alemu

Department of Epidemiology and Biostatistics, Institute of Public Health, College of Medicine and Health

Sciences, University of Gondar, Gondar, Ethiopia

Kyllike Christensson

Department of Women's and Children's Health, Division of Reproductive Health, Karolinska Institute, Sweden

\section{Esubalew Tesfahun}

Department of Public Health, College of Health Science, Debre Berhan University, Debre Berhan, Ethiopia.

\section{Helena Lindgren}

Department of Women's and Children's Health, Division of Reproductive Health, Karolinska Institute, Sweden

\section{Research Article}

Keywords: continuity of care, maternal satisfaction, midwife-led care, Amhara, Ethiopia

Posted Date: January 27th, 2021

DOl: https://doi.org/10.21203/rs.3.rs-151778/v1

License: (a) (1) This work is licensed under a Creative Commons Attribution 4.0 International License. Read Full License 
Evaluation of an Amharic-Language translation of continuity of care satisfaction tool among postnatal mothers in Ethiopia.

Solomon Hailemeskel ${ }^{1,} 5^{*}$, Kassahun Alemu², Kyllike Christensson ${ }^{3}$, Esubalew Tesfahun ${ }^{4}$ and Helena Lindgren ${ }^{3}$

$\underline{\text { Affiliations }}$

${ }^{1}$ School of Midwifery, College of Medicine and Health Science, University of Gondar, Gondar, Ethiopia

${ }^{2}$ Department of Epidemiology and Biostatistics, Institute of Public Health, College of Medicine and Health Sciences, University of Gondar, Gondar, Ethiopia

${ }^{3}$ Department of Women's and Children's Health, Division of Reproductive Health, Karolinska Institute, Sweden

${ }^{4}$ Department of Public Health, College of Health Science, Debre Berhan University, Debre Berhan, Ethiopia.

${ }^{5}$ Department of Midwifery, college of Health Science, Debre Berhan University, Debre Berhan, Ethiopia

*correspondence:

solomonhailemeske19@gmail.com 


\begin{abstract}
Background: Beginning in the 1990s, women's dissatisfaction with maternity services has been widely reported in the literature. However, there is a lack of consistency in the studies published over the three decades since then. The nature and availability of maternity services vary widely from country to country and even in single countries, the United States for example, there is no such thing as nationally uniform maternal care. We need cross cultural validated tools to measure women's satisfaction with maternity care. The study reported here aimed to develop a valid and reliable continuity of care satisfaction scale for use in Ethiopia, first by finding an appropriate English-language model and then translating that into an Amharic language version that in an appropriately modified form could be used for studies of postnatal mothers in Ethiopia.
\end{abstract}

Methods: An Amharic-language translation of a satisfaction with continuity of care tool was prepared based on an English-language questionnaire and this was then back translated. A team of experts analyzed the Amharic-language questionnaire as concerns the following elements: Face and content validity; quality of the forward and back translations; expert panel and pre-testing of the tool. A facility-based cross-sectional study was conducted among 329 postnatal mothers in Debre Berhan town health facilities, Ethiopia using the Amharic version of the questionnaire. Internal consistency of the tool (reliability) was checked by using Cronbach's alpha. We extracted a new factor structure by carrying out exploratory factor analysis (EFA). For the extracted factor structure, confirmatory factor analysis (CFA) was conducted, and the model fit was assessed.

Results: The translated tool was found to be acceptable by the experts and target groups. EFA yielded two subscales for each component of maternity care: "information provision and relationship with care providers" and "women's self-assessment on quality of care". The extracted factor structure had good convergent and discriminant validity. The tool has overall Cronbach's $\alpha$ value of $\mathbf{0 . 9 4}$. All three domains have acceptable internal consistency with $\alpha$ value of $>0.70$. CFA 
revealed a satisfactory fit between the questionnaire data and the model which provides support for the suggested factor structure identified by EFA.

Conclusion: This study confirmed that the Amharic-language continuity of care satisfaction evaluation tool is a valid tool for in future studies evaluating Ethiopian women's satisfaction with maternity care. The results from such studies could be used to aid in a trial of the continuity of care model in Ethiopia.

Key words: continuity of care, maternal satisfaction, midwife-led care, Amhara, Ethiopia 


\section{Background}

In maternity care, women's satisfaction is an indicator of the quality of the care they receive. Women who express satisfaction with the maternity care they have received very likely have benefited both physically and psychologically $[1,2]$. Some of the reasons for their satisfaction are being able to get consistent and useful information from the provider, receiving care from skilled providers who display a positive and respectful approach, and for even the mothers themselves being able to actively participate in decision making [2-4].

Maternity care is continuous in nature and continuity of care models are becoming more common with some studies showing that these models are improving the quality of care and satisfaction of mothers. The comparisons made in most satisfaction surveys are with older models, often seen as providing all too fragmented care, which later causes dissatisfaction with care [5].

Researchers in a number of countries have recommended dealing with these problems by establishing approaches that provide higher-level continuity of care in the belief that this will improve women's satisfaction as some studies indicate $(8,9)$. These studies $(8,9)$ and many others have found that the most important determinants of maternal satisfaction are high quality information [1,6]; experiencing a sense of control over the entire childbirth process [7-12], and the existence of a trusting relationship with midwives [13].

How a single pregnant mother will experience pregnancy, labour, delivery and postnatal care will depend in part on the care model followed with two extremes, one being the so-called traditional model [14], the other the continuity of care model. [8, 10, 15].

Many studies report on the availability of a wide variety of tools for measuring maternal satisfaction, each, at least in the early stages often focusing on only a select few aspects of maternity care such as antenatal care, labour and birth, an postnatal care. The literature is now so broad that attention is being paid to evaluating quality [16] and two Cochrane Reviews provide 
comparisons of a variety of models [16]. These reviews, which focused on midwife-led continuity models of maternity care found that there is little consistency in the approaches used and that there are many difficulties in measuring maternal satisfaction across different models of maternity care $[14,17]$. They make clear the need to develop robust tools that are culturally adapted, translated into the appropriate languages, and validated by using appropriate validation methods. In Ethiopia, no validated tool has been available in the Amharic language for assessing the mother's birth experience and satisfaction. Therefore, this study was set up with the aim of developing a questionnaire in the Amharic language that could be used determine how a group of mothers who had given birth in the Debre Berhan town health facilities, Amhara Regional State, Ethiopia viewed their experience and to determine if they saw advantages that might result if the continuity of care approach were to be introduced in Ethiopia.

\section{Methods}

\section{Aim}

The aim of this validation study was to determine if an existing English language questionnaire could not only be translated into a satisfactory Amharic language version but also be modified where necessary in order to be used in a survey in an Ethiopian setting.

\section{Research questions}

1. Are the scales in the Amharic-language questionnaire suitable for evaluating if maternal satisfaction could be measured with this version if a continuity of care model were to be employed? Ae these scales reliable and valid tools for the evaluation of women's experiences during the antenatal, labour, and postpartum periods of care? 
2. Which factors (as measured by subscales for the antenatal, labour and postpartum periods) might influence women's satisfaction and experiences if the women were to be offered the continuity of care model?

\section{Study setting}

The study was conducted among mothers who were interviewed 42 days after they had given birth at the Debre Berhan town health facilities, North Shoa Zone, Amhara Regional state, Ethiopia.

\section{Study design}

A facility based cross sectional study design was conducted from November 1, 2019 to January 30, 2020. The study describes the development and psychometric assessment of the Amharic continuity of care scale or questionnaire.

\section{Sample size determination}

The sample size required for the study was determined based on the number of questions present in the questionnaire. To get the largest possible sample size, we used 10 respondents for one variable ratio which was suggested by scale development studies in which five to ten subjects were found to be needed for each item [18]. Considering the number of items in the draft scale the final calculated sample size for a 33-question questionnaire was 330 mothers.

\section{Sampling technique}

Consecutive postnatal mothers who came to the health facilities 42 days after giving birth during the study period who fulfilled the inclusion criteria were added to the study group until the required sample size achieved. 


\section{Inclusion and exclusion criteria}

Postnatal mothers who visited the health facilities 42 days after delivery and were willing to participate in the study were included in the study. Mothers who had visited the health facilities before the end of the postnatal period were excluded.

\section{Procedures followed for scale development}

Five steps were taken in development of the Amharic version of the continuity of care satisfaction scale: literature review and selection of a valid and reliable English version satisfaction scale for the continuity of care model, translation of the selected scale to the Amharic language, content validity testing, administration of a draft scale and psychometric testing.

\section{Literature review and selection of an appropriate English version tool}

In the first stage, factors associated with satisfaction with maternity care as practiced in the continuity of care model were explored by making a comprehensive review of the literature. The search focused on finding an English-language tool for use in evaluating the three aspects of the continuity of care model: antenatal, labour and delivery care, and postnatal care. The systematic review by Perlman and Davis [19] helped us to identify a tool well suited for translation to Amharic that we could use. Four tools were found to be appropriate for evaluating maternal satisfaction. We found the three key elements to be studied were: level of satisfaction with antenatal care, intrapartum care and postnatal care.All three of these elements are present no matter what model guides maternity care but we were only interested in examining them in the context of a continuity of care model. The tool we chose has 33 Likert questions designed to aid in evaluating the specific effect of employing a midwife-led team on maternal satisfaction [5]. Of these 33, 10 measured satisfaction with antenatal care, 10 to assess satisfaction with labour and delivery care, and 13 to measure satisfaction with postnatal care. Responses to 33 questions were to be registered on a five- 
point Likert scale with 5 indicating strongly agree and 1 strongly disagree. In all the three domains of care, the questions were framed to evaluate the quality of communication and of the relations hip between the mother and the health-care person, Permission was obtained from the original tool developer to translate the tool into the Amharic language and to then validate this version. Content/face validity and pilot testing were undertaken to achieve these ends. We found that measuring satisfaction with each of the three elements was appropriate for measuring overall satisfaction with care offered in a continuity of care system.

\section{Translation of the selected tool to Amharic language}

In translating the English version [5] into the Amharic language, the five-step procedure outlined by Wild [20] was followed: The five steps are: 1) evaluate face and content validity 2) forward translation and expert panel discussion, 3) back translation and, comparison of the back translation with the original by expert panel, 4) pre-testing and 5) psychometric testing and constructive and criterion validity

\section{Step 1: Face and Content validity}

The final questionnaire in the Amharic language was presented to six experts all of whom have Amharic as their first language (two MSc midwife, Reproductive health expert, Medical doctor and two maternity nurse specialist) to review and evaluate the relevance of items to the domain of contents represented in the tool using the content validity index (CVI). The CVI is a widely used index that provides evidence for content validity by using ratings of item relevance by a panel of content experts. Experts rate each item as: 1, not relevant; 2, somewhat relevant; 3, quite relevant; 4, highly relevant. Items with ratings of either 3 or 4 are considered to be relevant. The average item CVI score is the average CVI score of the scale [21,22] and agreement for relevance at the item level should be at least $80 \%$. Accordingly, this tool has a CVI score of 1.0 for each item. 


\section{Step 2: Forward translation and expert panel discussion}

Translation was done by two independent translators (masters in maternal and reproductive health with background in midwifery and an English language instructor with a minor in the Amharic language). The first translator was knowledgeable about the content of the tool and the second translator was a language expert. Both were independent native Amharic speakers and fluent in the English language. The two translators sat together with the principal investigator and a discussion was held among them. Finally, a common Amharic language document was created using the two translated versions to develop a consensus. In line with this expert panel (6 in number) by involving different professionals (midwife, reproductive health, medical doctor and nurse) it was possible to evaluate the final forward and back translations and pretesting results. Moreover, the expert panel was asked to evaluate the importance of each item in the tool with regard to each person's subdomain.

\section{Step 3: back translation and, comparison of the back translation version by the expert panel}

The Amharic language version was translated back to the original English language. This was done by using two translators different from the first translator and blinded for both the original and translated documents. These two translators had Amharic as first language - born to mothers who spoke Amharic - but had also become fluent in English. The back translation was done independently by each. Each back translation was compared with the original English-language document. Then the two translators compared the two Amharic language documents and reconciled any differences by mutual agreement to produce a final version ready for pilot testing.

\section{Step 4: Pre-testing of the pre final tool}

Pre-testing of the Amharic-language questionnaire was carried out by interviewing groups of 10 postnatal mothers for each section to be tested who were native speakers of the Amharic language. 
Each was asked to evaluate the instruction, the item and possible misunderstanding of words, clarity of the response options and content format clarity. Discussion were made with the research team on the response of the participants to make changes in the tool if necessary.

\section{Step 5: Full psychometric testing of the Amharic tool}

\section{Construct validity}

In the literature, it is recommended that factor analysis be done to identify potential underlying dimensions/subscales in a scale [23-26]. In this study, to explore the factor structure of the dataset, exploratory factor analysis with Principal Axis Factoring and Promax with Kaiser Normalization rotation were used. Moreover, to justify the compliance between exploratory factors and to confirm the protection of factor structure, confirmatory factor analysis was done [27]. For the confirmatory factor analysis, maximum likelihood estimation was used for validation of the model. The goodness of fit indices were assessed by using Tuker Lewis Index (TLI; > 0.90), Comparative Fit Index (CFI; > 0.90), Root Mean Square of Approximation (RMSEA; < 0.08) and Standardized Root Mean Residual (SRMR; < 0.08) [28].

\section{Subscale analysis}

For evaluating the internal consistency of the tool, the subscales presented in the tool (antenatal care, labour and delivery care and postnatal care) were evaluated in terms of their correlation with the total satisfaction scale as well as the item-subscale correlation.

\section{Item analysis}

According to the literature, in order to have a stronger relationship with the item and the nature of content intended to be measured there must be a higher correlation coefficient. The correlation 
coefficients $<0.25-0.30$ and $>0.70$ are not preferred [23-25]. In this study, 0.25 was taken as the lower limit for item-total correlations.

\section{Internal reliability}

Cronbach's $\alpha$ coefficient is concerned with the degree of interrelatedness between a set of items designed to measure a single construct. The internal consistency of a midwife-led continuity of care satisfaction tool was measured by determining Cronbach's $\alpha$ coefficient for each domain. A Cronbach's $\alpha$ value higher than 0.7 is considered as indicating that the tool is satisfactory [23, 24]. The extracted tool was also evaluated for convergent and discriminant validity. Convergent validity is the extent to which scale correlates positively with other measures of the same construct as measured by composite reliability ( $C R \geq 0.7)$, and the average variance extracted (AVE $\geq 0.5$ ). AVE $<$ CR was used to establish convergent validity [29].

\section{Statistical analysis}

The data were checked for completeness and consistency and partially completed questiond were removed from the analysis. Then the cleaned and coded data were entered into SPSS version 20 windows for exploratory factor analysis. Confirmatory factor analysis (CFA) was done by using Analysis of Moment Structures (AMOS; version 25, Chicago, IL). Descriptive statistics and independent t-test were done using STATA version 14 software. Sociodemographic characteristics, continuity of care, past and current obstetrics and gynecologic information were described with descriptive statistics. 


\section{Ethical approval}

Ethical approval was obtained from the Institutional Review Board of University of Gondar. Permission letter was obtained from regional health bureau, zonal health department and hospital administration. An informed and signed consent was obtained from each participant. Participants were informed that their participation in this study was voluntary, the information they gave remains confidential and is used only for research purpose. Participants were told that they could also withdraw from participating in the study at any time.

\section{Results}

\section{Sociodemographic characteristics of study participants}

A total of 330 postnatal mothers were invited to participate in this study. One was excluded from the final analysis due to incomplete response. A total of 329 postnatal mothers participated giving a response rate of $99.6 \%$. Of these 329 mothers, $145(44.07 \%)$ mothers were in the midwife-led group and $184(55.93 \%)$ were in the shared-care group. There was no significant age difference between the two groups ( $\mathrm{p}$ value $\mathbf{0 . 9 7}$ ). The mean age in the in midwife-led group was 28.17 years and in the shared-care group 28.15 years. The majority in both groups were between 19 and 34 years old when they married $122(84.1 \%)$ in the midwife-led and $142(77.2 \%)$ in the shared care group. The majority in both groups became pregnant for the first time between age 21 and $30-$ Midwife led 109 (74.5\%) and shared care 145 (78.8\%) More than half of the mothers in both groups were multigravida. The distribution in the two groups was: Midwife led $83(57.2 \%)$, shared care $95(51.6 \%)($ Table 1$)$ 
Table 1: Sociodemographic characteristics of study participants, North Shoa zone, Debre

Berhan town, Ethiopia $(n=329)$

\begin{tabular}{|c|c|c|c|c|}
\hline Variable & Category & Midwife-led group & $\begin{array}{l}\text { Shared model of } \\
\text { care group }\end{array}$ & p-value \\
\hline \multirow[t]{6}{*}{ Age of the mother } & $<20$ years & $3(2.1 \%)$ & $4(2.2 \%)$ & \\
\hline & 20-24 years & $32(22.1 \%)$ & $43(23.4 \%)$ & \\
\hline & 25-29 years & $55(37.9 \%)$ & $72(39.1 \%)$ & \\
\hline & $30-34$ years & $40(27.6 \%)$ & $41(22.3 \%)$ & \\
\hline & $>=35$ years & $15(10.3 \%)$ & $24(13.0 \%)$ & \\
\hline & $\operatorname{Mean}( \pm S D)$ & 28.17 (4.76) & $28.15(5.00 \%)$ & 0.97 \\
\hline Age of the mother at & $<=18$ years & $5(3.4 \%)$ & $7(3.8 \%)$ & \\
\hline \multirow[t]{3}{*}{ first marriage } & 19-24 years & $122(84.1 \%)$ & $142(77.2 \%)$ & \\
\hline & $>=25$ years & $18(12.4 \%)$ & $35(19.0 \%)$ & \\
\hline & $\operatorname{Mean}( \pm S D)$ & $22.15(3.27 \%)$ & $22.44(3.36 \%)$ & 0.43 \\
\hline \multirow[t]{4}{*}{ Age at first pregnancy } & $<=20$ years & $34(23.4 \%)$ & $37(20.1 \%)$ & \\
\hline & 21-30 years & $108(74.5 \%)$ & $145(78.8 \%)$ & \\
\hline & $>=31$ years & $3(2.1 \%)$ & $2(1.1 \%)$ & \\
\hline & $\operatorname{Mean}( \pm$ SD $)$ & $23.71(3.47 \%)$ & $24.15(3.61 \%)$ & 0.25 \\
\hline Number of pregnancy & Prim gravida & $62(42.8 \%)$ & $89(48.4 \%)$ & 0.31 \\
\hline (gravidity) & Multigravida & $83(57.2 \%)$ & $95(51.6 \%)$ & \\
\hline Number of delivery & Primipara & $63(43.4 \%)$ & $89(48.4 \%)$ & 0.37 \\
\hline (parity) & Multipara & $82(56.6 \%)$ & $95(51.6 \%)$ & \\
\hline Mothers level of & Unable to read and write & $10(6.9 \%)$ & $7(3.8 \%)$ & 1 \\
\hline \multirow[t]{3}{*}{ education } & Able to read and write & $5(3.4 \%)$ & $5(2.7 \%)$ & 0.65 \\
\hline & Primary and secondary education & $72(49.7 \%)$ & $70(38.0 \%)$ & 0.52 \\
\hline & Diploma and degree & $58(40.0 \%)$ & $102(55.4 \%)$ & 0.07 \\
\hline
\end{tabular}




\section{Findings of face and content validity}

There was general consensus among the six experts that all the items in the questionnaire were relevant. The content validity index was 1.0. This indicates good validity. None of the items was rejected by the experts, but they recommended changing the wording of a few items to enhance face validity and content validity of the tool. Rewording of such items was carried out to remove any ambiguous phrasing and to promote easier understanding of the items. The expert panel also suggested three items that were added to further enhance domain coverage. All the items in the continuity of care satisfaction scale were required for domain coverage. After modifying the questionnaire based on the feedback from the expert panel, the questionnaire was then further tested in a pilot study that involved cognitive testing and test-retest. According to participant's response, we found the questions to be clear and understandable by the community and that they could be used to achieve face validity.

\section{Reliability and item analysis}

All the domains had positive and statistically significant item-total correlation coefficients $>0.25$ $(\mathrm{r}=0.27-0.67)$. Accordingly, items with low item total correlations $(<0.25)$ were supposed to be deleted. But in this study, there was no item with correlation value of $<0.25$.

The internal consistency of the Amharic version of the questionnaire had an overall Cronbach's $\alpha$ value of 0.94. All of the three domains have an acceptable internal consistency with $\alpha$ value of 0.93 for antenatal care service, 0.91 for labour and delivery service and 0.90 for postnatal care service (Table 2.1, 2.2 and 2.3). Cronbach's $\alpha$ coefficient for the antenatal care subscales ranged from 0.798 to 0.957 , for labour and delivery subscale ranged from 0.626 to 0.917 and from 0.769 to 0.899 for postnatal subscale. As seen in Table 2.1 to 2.3 , the magnitude of change in Cronbach's 
alpha was almost uniform across items, and in no instances did removal of an item from the scale result in an increase in the value of Cronbach's alpha.

Table 2.1 Internal consistency, item-total correlations, and alpha if item deleted from the Amharic continuity of care satisfaction questioner for Antenatal care sub domain

\begin{tabular}{|c|c|c|c|}
\hline Item & Item description & $\begin{array}{l}\text { Item total } \\
\text { correlation }\end{array}$ & $\begin{array}{l}\text { Alpha if } \\
\text { the item } \\
\text { deleted }\end{array}$ \\
\hline 1 & At my checkup I was asked whether I had questions & 0.656 & 0.819 \\
\hline 2 & Midwife informed me what was happening & 0.799 & 0.798 \\
\hline 3 & $\begin{array}{l}\text { I was always given an active say in decision about my care in } \\
\text { pregnancy }\end{array}$ & 0.585 & 0.822 \\
\hline 4 & My worries and concern about pregnancy were taken seriously & 0.668 & 0.814 \\
\hline 5 & Midwife provided reassurance when needed & 0.748 & 0.813 \\
\hline 6 & At my checks, the midwife seemed rushed & 0.848 & 0.949 \\
\hline 7 & Care during pregnancy was provided in a safe and competent way & 0.837 & 0.957 \\
\hline 8 & $\begin{array}{l}\text { Happy about the emotional support received from midwives during } \\
\text { pregnancy }\end{array}$ & 0.888 & 0.945 \\
\hline 9 & Happy with the physical care received by midwives during pregnancy & 0.916 & 0.943 \\
\hline 10 & Overall care during pregnancy was good & 0.932 & 0.941 \\
\hline Overall & Cronbach's alpha (10 Antenatal care related items ) & & 0.932 \\
\hline Averag & e variance extracted (AVE) & & 0.63 \\
\hline Compo & site reliability $(\mathrm{CR})$ & & 0.94 \\
\hline
\end{tabular}


Table 2.2 Internal consistency, item-total correlations, and alpha if item deleted from the Amharic continuity of care satisfaction questioner for Labour and Delivery care sub domain

\begin{tabular}{|c|c|c|c|}
\hline Item & Item description & $\begin{array}{l}\text { Item total } \\
\text { correlation }\end{array}$ & $\begin{array}{l}\text { Alpha if } \\
\text { the item } \\
\text { deleted }\end{array}$ \\
\hline 1 & Midwife informed me what was happening during labour & 0.651 & 0.645 \\
\hline 2 & Active say in decision about my care during labour & 0.835 & 0.626 \\
\hline 3 & The midwives were encouraging & 0.540 & 0.693 \\
\hline 4 & I often felt the midwives/doctors were very rushed & 0.703 & 0.901 \\
\hline 5 & The midwives provided reassurance if I needed it & 0.605 & 0.917 \\
\hline 6 & Care during labour and birth was provided in a safe way & 0.787 & 0.904 \\
\hline 7 & Care during labour and birth was provided in a competent way & 0.807 & 0.898 \\
\hline 8 & I was happy with the emotional support I received from midwives & 0.771 & 0.897 \\
\hline 9 & My privacy needs were well respected during labour and birth & 0.794 & 0.896 \\
\hline 10 & Overall, how would you describe your care in labour and birth & 0.878 & 0.887 \\
\hline Overal & Cronbach's alpha (10 Labour and delivery care related items) & & 0.907 \\
\hline Averag & variance extracted (AVE) & & 0.55 \\
\hline Compc & site reliability (CR) & & 0.92 \\
\hline
\end{tabular}


Table 2.3 Internal consistency, item-total correlations, and alpha if item deleted from the Amharic continuity of care satisfaction questioner for postnatal care sub domain

\begin{tabular}{llc}
\hline Item Item description & $\begin{array}{l}\text { Item total Alpha if } \\
\text { correlation the item } \\
\text { deleted }\end{array}$
\end{tabular}

$1 \quad$ The midwives always kept me informed about what was happening in $0.459 \quad 0.797$ the postnatal ward

2 I was always given an active say in decisions about care of my baby $\quad 0.395 \quad 0.814$ and myself

3 I was given the advice and support I needed with breast feeding $\quad 0.427 \quad 0.797$

4 I was given the advice and support I needed about how to handle, $\quad 0.693 \quad 0.783$ settle or look after my baby

$\begin{array}{lllll}5 & \text { I was given the advice and support I needed about any problems with } & 0.767 & 0.777\end{array}$ the baby's health and progress

6 I was given the advice and support I needed about my own health and $0.797 \quad 0.769$ recovery after the birth

7 The midwives were sensitive and understanding $\quad 0.337 \quad 0.806$

$\begin{array}{llll}8 & \text { The midwives were encouraging and reassuring } & 0.354 & 0.899\end{array}$

$9 \quad$ I often felt the midwives were very rushed $\quad 0.879 \quad 0.846$

10 Care in hospital after the birth was provided in a safe and competent $\quad \begin{array}{lll}0.417 & 0.877\end{array}$ way

11 I was happy with the emotional and physical aspects of care given by $0.691 \quad 0.850$ the midwives

12 Overall, the care received in hospital after the birth was very good $\quad 0.851 \quad 0.839$ 


\begin{tabular}{lc}
\hline $13 \quad$ Overall, the care baby received in hospital after the birth was very & 0.978 \\
good & 0.825 \\
Overall Cronbach's alpha (13 postnatal care related items) & $\mathbf{0 . 9 0 1}$ \\
Average variance extracted (AVE) & 0.43 \\
Composite reliability (CR) & 0.89 \\
\hline
\end{tabular}

\section{Exploratory factor analysis}

The tool demonstrated very good sample adequacy for factor analysis (Kaiser Meyer Olkin (KMO) of 0.933 for antenatal care domain, 0.933 for labour and delivery domain and 0.917 for postnatal care domain and Bartlett's Test of Sphericity becomes statistically significant $(P<0.000)$ for each domain indicating appropriateness of the data set for factor analysis and the presence of correlation among items.

Evaluation of construct validity through Principal Axis Factoring and Promax with Kaiser Normalization rotation yielded 2 factors for antenatal care domain, each with eigenvalues $>1.0$ that together explained approximately $67.325 \%$ of the variance in the scale, for labour and delivery domain 2 factors each with eigenvalues $>1.0$ and $57.99 \%$ variance and for postnatal care domain 2 factors each with eigenvalues $>1$ and $49.87 \%$ variance in the scale (Tables 3 ). Factor loadings of all items were sufficient $(>0.30)$. Factor loadings indicate that individual item reliability was adequate for all items, ranging from 0.337 to 0.978 for all the factors identified in each domain. The factor analysis divided the antenatal care domain items into two factors. Factor 1 from \#1 to \# 5 and named as provision of information and relationship during antenatal care. Factor 2 which was designated as women's assessment of quality of care during antenatal care includes \#6 to \#10. Similarly, for labour and delivery domain the exploratory factor analysis provides two factors. Factor one includes item \# 1 to \#3 which is represented as provision of information and relationship 
during labour and delivery. Factor two incudes item number 4 to 10 and designated as women assessment of quality of care during labour and delivery. For the postnatal care domain, the factor analysis provides two factors. Factor one includes item \# 1 to \# 7 named as provision of information and relationship during postnatal period. Factor two includes item \# 8 to 13 and designated as women assessment of quality of care during postnatal care.

Table 3 Exploratory factor analysis with Principal Components Promax Factor Loadings for the Amharic continuity of care satisfaction questionnaire

\section{Antenatal care Item}

$1 \quad$ At my checkup I was asked whether I had questions

2 Midwife informed me what was happening

3 I was always given active say in decision about my care in pregnancy

$4 \quad$ My worries and concern about pregnancy was taken seriously

5 Midwife provided reassurance when needed

6 At my checks the midwife seemed rushed

7 Care during pregnancy was provided in a safe and competent way

$8 \quad$ Happy by the emotional support received from midwives during pregnancy

9 Happy with the physical care received by midwives during pregnancy

10 Overall care during pregnancy was good

$\%$ of variance

Cumulative \%
Factor I Factor II

0.656

0.748

0.848

0.837

0.888

0.916

0.932

59.274

8.051

59.274 


\section{Labour and delivery care Item}

1 Midwife informed me what was happening during labour

2 Active say in decision about my care during labour

3 The midwives were encouraging

$4 \quad$ I often felt the midwives/doctors were very rushed

0.703

5 The midwives provided reassurance if I needed it 0.605

6 Care during labour and birth was provided in a safe way

7 Care during labour and birth was provided in a competent way

8 I was happy with the emotional support I received from midwives

9 My privacy needs were well respected during labour and birth

10 Overall, how would you describe your care in labour and birth

Cumulative $\%$

\section{Postnatal care Item}

1 The midwives always kept me informed about what was happening in the postnatal ward

2 I was always given an active say in decisions about care of my baby and myself

3 I was given the advice and support I needed with breast feeding

4 I was given the advice and support I needed about how to handle, settle or look after my baby 
5 I was given the advice and support I needed about any problems with the baby's health and progress

6 I was given the advice and support I needed about my own health and recovery after the birth

7 The midwives were sensitive and understanding

8 The midwives were encouraging and reassuring

9 I often felt the midwives were very rushed

10 Care in hospital after the birth was provided in a safe and competent way

11 I was happy with the emotional and physical aspects of care given by the midwives

12 Overall, the care received in hospital after the birth was very good

13 Overall, the care baby received in hospital after the birth was very good 0.978 $\%$ of variance

\section{Confirmatory factor analysis}

Confirmatory factor analysis was done to justify the factors identified in the exploratory factor analysis. In confirmatory factor analysis the results of the fit indices for antenatal care domain were $x^{2} 71.137(p<0.001)$, degrees of freedom $=34$, root mean square error of approximation $($ RMSEA $)=0.058$, standardized root mean square residual $(\mathrm{SRMR})=0.044$, comparative fit index $(\mathrm{CFI})=0.986$, Tucker-Lewis index $(\mathrm{TLI})=0.982$, Non-normed fit index $(\mathrm{NNFI})=0.974$, goodness of fit index $(\mathrm{GFI})=0.956$ and adjusted goodness of fit index $(\mathrm{AGFI})=0.929$ (figure 1 ). 
Similarly for labour and delivery domain the results of the fit indices were $\mathrm{x}^{2} 44.634(\mathrm{p}=0.105)$, degrees of freedom $=34$, root mean square error of approximation $($ RMSEA $)=0.031$, standardized root mean square residual $(\mathrm{SRMR})=0.047$, comparative fit index $(\mathrm{CFI})=0.994$, Tucker-Lewis index $(\mathrm{TLI})=0.992$, Non-normed fit index $(\mathrm{NNFI})=0.976$, goodness of fit index $(\mathrm{GFI})=0.974$ and adjusted goodness of fit index $(\mathrm{AGFI})=0.958$ (figure 1 ).

Finally, for postnatal care domain the results of the fit indices were $x^{2} 185.5(p=0.000)$, degrees of freedom $=64$, root mean square error of approximation $($ RMSEA $)=0.076$, standardized root mean square residual $(\mathrm{SRMR})=0.094$, comparative fit index $(\mathrm{CFI})=0.942$ and Tucker-Lewis index $(\mathrm{TLI})=0.930$, Non-normed fit index $(\mathrm{NNFI})=0.915$, goodness of fit index $(\mathrm{GFI})=0.920$ and adjusted goodness of fit index $(\mathrm{AGFI})=0.886$ (figure 1). Assessment of acceptable model fit in the confirmatory factor analysis concluded that the model given after exploratory analysis had the best fit according to the results of $\mathrm{x}^{2}$, RMSEA, SRMR, CFI and TLI. 

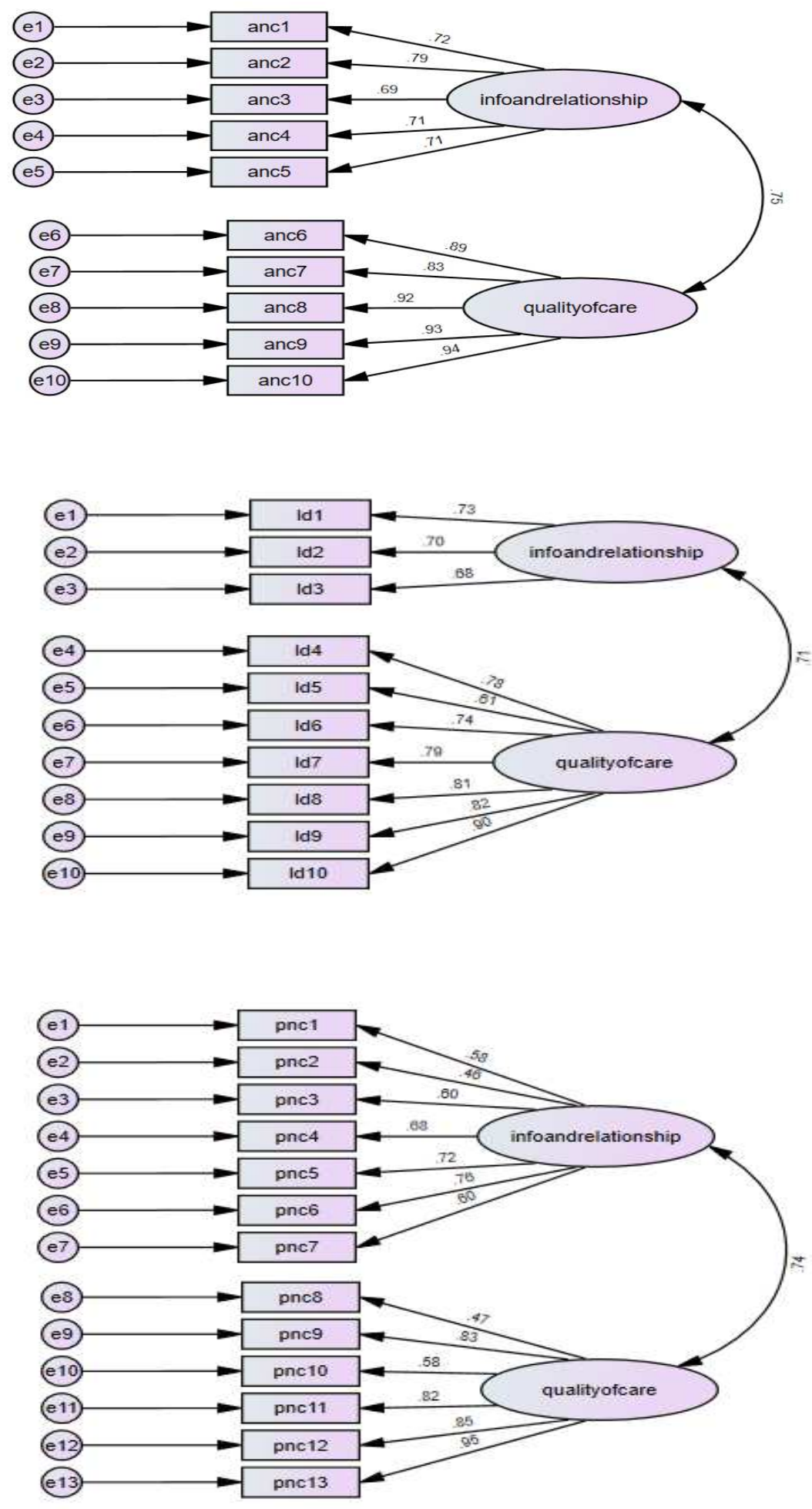

Fig. 1 Confirmatory factor analysis model (Full text annotations of the latent variables for antenatal care, labour and delivery and post-natal care subdomains) 


\section{Convergent validity}

Convergent validity of the extracted construct was evaluated by average variance extracted (AVE) and composite reliability (CR) tests. The result demonstrated that antenatal care domain has AVE $=0.63$ and $\mathrm{CR}=0.94$, labour and delivery domain has $\mathrm{AVE}=0.55$ and $\mathrm{CR}=0.92$ and postnatal care domain has $\mathrm{AVE}=0.43$ and $\mathrm{CR}=0.89$. The obtained result indicated that the value of $\mathrm{CR}>$ 0.7, AVE $<\mathrm{CR}$ and AVE $>0.5$ for antenatal care and labour and delivery domain. Whereas it was $>0.4$ for the postnatal care domains, indicating convergent validity of the extracted tools.

\section{Known-groups validity}

Known-groups validity was evaluated based on different models of maternal health care types. This study assumed that mothers receiving midwife-led continuity of care would report greater satisfaction than mothers receiving shared model of care. Thus, we selected two subgroups among postnatal mothers, a midwife-led group (145 cases) and a shared model of care group (184 controls) and we then compared the mean satisfaction scores between the two groups by t-tests. There were significant differences for antenatal care labour and delivery care and postnatal care domains (Mann -Whitney U test; p- value <0.001) (table 4) 
Table 4: Comparison of the Amharic continuity of care satisfaction domain scores between midwife-led group and shared model of care groups

\begin{tabular}{llllll}
\hline Satisfaction domain & Midwife-led & Shared model & of & Mann -Whitney & P-value \\
& group & care group & U test & \\
\hline ANC satisfaction & $145(182.03)$ & $184(151.58)$ & 10870 & $<0.0001$ \\
Labour and Delivery & $145(192.83)$ & $184(143.07)$ & 9303 & $<0.0001$ \\
PNC satisfaction & $145(204.29)$ & $184(134.04)$ & 7643 & $<0.0001$ \\
\hline
\end{tabular}

\section{Discussion}

In this study we identified the multidimensionality of measurements of women's satisfaction with maternity care. The Amharic version continuity of care satisfaction scale was found to be content valid and translated to Amharic language successfully. Exploratory factor analysis identified two factor structures ("information provision and relationship with care providers" and "women's selfassessment on quality of care") for each domain of the scale. The extracted factor structures were found to be internally consistent with Cronbach's alpha value $>70$. The appropriateness of the extracted dataset for the model was evaluated by confirmatory factor analysis and found to have good model fit with good known group and convergent validity.

Studies designed to investigate women's childbirth experience and satisfaction with care have identified the multidimensional structure of factors affecting maternal satisfaction [30, 31]. Therefore, measurement tools that evaluate maternal level of satisfaction with continuity of care need to be evaluated for their reliability and validity [32]. The support that women received during antenatal care, childbirth, postnatal care, personal and organizational factors have associations with positive or negative perceptions of birth experience and satisfaction with care. Multiple 
concepts underpin the construct of maternal satisfaction with care. These constructs were largely framed positively in terms of having choice and control, organization of maternity services, antenatal preparation, communication with health professionals, privacy, medical procedures, midwifery care, emotional support, pain relief, presence of significant others during birth, being informed, participation in decision making, infant care, postpartum care, continuity of care and having good quality of care, and dissatisfaction were reflected with the absence of these characteristics [33-36]. However, relatively few measures have been developed and appropriately tested with sufficiently large populations. In Ethiopian context, tools used to measure maternal satisfaction with continuity of care had not previously been translated into the Amharic language and had never been validated. In this present study, the continuity of care satisfaction tool was translated into the Amharic language and its reliability and validity were satisfactorily assessed.

The continuity of care satisfaction tool has good content validity. According to the expert ratings, the content validity of the scale was found to be very good. This result showed that the items in the continuity of care satisfaction tool reflected the main aspects of satisfaction with continuity of care. Also, the significant correlation coefficients between the total score and item scores, as well as with the subscales (domain) indicated their association with maternal satisfaction in relation to each aspects of continuity of care (satisfaction with antenatal care, labour and delivery and postnatal care). Each item in the scale was primarily evaluated in terms of its appropriateness to Ethiopian culture and context through literature review, content validity evaluation by expert views and pilot testing on postpartum women. Finally, the continuity of care satisfaction tool has been translated and culturally adapted to Amharic language.

In this study, the Amharic version of continuity of care satisfaction tool was found to have excellent overall internal consistency $(\mathbf{0 . 9 4})$. Besides, all three domains have an acceptable internal consistency with $\alpha$ value of 0.93 for antenatal care service, 0.91 for labour and delivery service 
and 0.90 for postnatal care service. The scale demonstrated good supportive psychometric properties and indicated that the subscales identified in each domain are internally reliable. This finding was found to be higher with the minimum threshold for reliability test value of 0.7 [37], suggesting all subscales identified in each domain of care are internally reliable. The findings concerning the tool can be considered as appropriate in terms of its internal consistency and indicate that the tool can be useful for studies focusing on measuring maternal satisfaction along the continuity of care spectrum or explicitly for each domain of the continuity of care.

In this study we conducted exploratory factor analysis first to identify the possible underlying constructs under each domain of the continuity of care satisfaction tool. Then we did confirmatory factor analysis for assessing the appropriateness of the extracted dataset for the model. Accordingly, the new dataset provides two extracted factors for each domain of maternal health care. The first factor extracted weas related to information provision and relationship with the provider and the second factor was women's self-assessment on the quality of care. Items extracted in the first factor identified in the three domains had a component of communication and the relationship, communication and the provision of information and women's involvement in decision making. This dimension of satisfaction measurement were found to be consistent with other studies in which women involvement in decision making and feeling in control during child birth were frequently reported as important factor on influencing maternal satisfaction [2, 32, 3840]. This subscale identified in all subdomains confirmed the importance of receiving information, the presence of informed choice and communication skill for mother's satisfaction.

The women's assessment regarding the quality of care she received explained the largest percentage of variance in the total scale in each domain. This is not surprising given that pregnant mothers are focused on the quality of care they received in relation to improving their health and wellbeing of their baby [41]. This finding is further supported by different studies that have 
reported that midwifery support for women in continuity of care increases maternal satisfaction $[34,42,43]$. Besides, meeting expectations during care provision and women's experience for labour and birth are well known significant predictors of maternal satisfaction with care [34, 39].

In general several important factors influence the overall birth experience and satisfaction of women with maternity care $[44,45]$. These include: competency of the provider, respect for privacy, dignity, and respect (addressed in the subscale women's self-assessment on the quality of care); compassion and understanding, receiving information and involvement in decision-making (addressed in the subscale information and communication).

All the factors identified through the EFA in the current study supported the concept of satisfaction with maternity care as a multidimensional construct, consistent with the literature reviewed indicating that the need for developing a multidimensional tool. The factors extracted in each domain have met the needs of at least three items in each extracted factor as suggested by other scholars [46].

All of the extracted factors for each domain of maternal health care showed acceptable Cronbach alpha and demonstrated good convergent and known group validity. The satisfaction level of women in midwife-led continuity of care group were higher than women in the shared model of care. This indicates that the tool is important for measuring level of maternal satisfaction in maternity care. 


\section{Strength and limitation of the study}

In this study, the tool was able to evaluate satisfaction for each component of maternity care (antenatal care, labor and delivery care and postnatal care). Besides, the tool has a communication, relationship, women's involvement in decision making and women's self-assessment of quality of care components as measurement variable for satisfaction. The translated tool was tested for recommended psychometric properties and demonstrated high reliability and validity.

Although the sample size was adequate for this study, the fact that this research was implemented in Debre Berhan town health facilities can be considered as a limitation of the study. Further studies are needed to test the reliability and validity of the tool in rural communities.

\section{Conclusion}

We conclude that the translated Amharic version continuity of care satisfaction scale is a valid, reliable and acceptable instrument for measuring women's experiences and satisfaction in the entire course of maternity care in the health care system. In the future, the tool may contribute to assessment of the quality of care and service developments given by health care providers in continuity of care model. It can be also used as a reference for other researchers used to measure maternal satisfaction and experience related with continuity of care model. 


\section{Declarations}

\section{Acknowledgments}

We would like to thank the subject matter experts and language translators for their professional contribution in the development of the scale. We would like to thank the original English language developers for their willingness to translate and use the tool in Amharic language. We are also thankful for postnatal mothers who participated and providing us their response in this study, as well as the participating health facilities for allowing us to conduct the data collection.

\section{Author contributions}

SHB facilitated the scale development and language translation. SHB drafted the initial manuscript. SHB, KAG, KC, ETA and HL participated in the study design and data analysis and reviewed the final manuscript. All authors contributed toward analyzing data, drafting and revising the paper, giving final approval of the version to be published and we agreed to be accountable for all aspects of the work.

\section{Ethics approval and consent to participate}

The study was approved by the Institutional Review Board at the University of Gondar (O/V/P/RCS/05/1050/2019 on March 2019) and all methods were carried out in accordance with relevant guidelines and regulations. An informed and signed consent was obtained from each participant. Participants were informed that their participation in this study was voluntary, the information they gave remains confidential and is used only for research purpose. Participants were told that they could also withdraw from participating in the study at any time.

\section{Availability of data and materials}

The datasets used and/or analyzed during the current study are available from the corresponding author on reasonable request.

\section{Competing interests}


The authors report no conflicts of interest in this work

\section{Funding}

No funding to be reported

\section{Abbreviations}

AGFI: Adjusted Goodness of Fit Index

AMOS: Analysis of Moment Structures

ANC: Antenatal Care

AVE: Average Variance Extracted

CFA: Confirmatory Factor Analysis

CFI: Comparative Fit Index

CR: Composite Reliability

CVI: Content Validity Index

EFA: Exploratory Factor Analysis

GFI: Goodness of Fit Index

KMO: Kaiser Meyer Olkin

NNFI: Non-normed fit index

PNC: Postnatal Care

RMSEA: Root Mean Square Error of Approximation

SRMR: Standardized Root Mean Square Residual

TLI: Tucker-Lewis Index 


\section{Reference}

1. Waldenström U, Nilsson CA: Women's satisfaction with birth center care: a randomized, controlled study. Birth 1993 Mar, 21( 1):3-13.

2. Waldenström U: Continuity of carer and satisfaction. Midwifery 1998, 14(4):207-213.

3. Bruinsma F, Brown S, Dary MA: Having a baby in Victoria 1989-2000: women's views of public and private models of care. Aust $N$ Z J Public Health 2003, 27(1):2026.

4. Fellowes D, Horsley A, Rochefort $\mathrm{J}$ : Is continuity of carer a top priority for all women? British Journal of Midwifery 1999, 7(1):36-40.

5. Waldenström U, Brown S, McLachlan H, Forster D, Brennecke S: Does team midwife care increase satisfaction with antenatal, intrapartum and postpartum care? A randomized controlled trial. Birth 2000, 27(3):156-167.

6. Fleissig A: Are women given enough information by staff during labour and delivery? Midwifery 1993, 9(2):70-75.

7. Hundley V, Milne J, Glazener C, Mollison J: Satisfaction and the three C's: continuity, choice and control. Women's views from a randomised controlled trial of midwifeled care. BJOG 1997, 104(11):1273-1280.

8. Homer CS, Davis GK, Cooke M, Barclay LM: Women's experiences of continuity of midwifery care in a randomised controlled trial in Australia. Midwifery 2002, 18 (2 ):102-112 .

9. Hodnett E: Continuity of caregivers for care during pregnancy and childbirth ("Cochrane Review") in The Cochrane Library, Issue 3. In.: Oxford, Update Software; 2001. 
10. Green JM, Coupland VA, Kitzinger JV: Expectations, experiences, and psychological outcomes of childbirth: a prospective study of 825 women. Birth 1990, 17( 1):15-24.

11. Brown S, Lumley J: Satisfaction with care in labour and birth: a survey of 790 Australian women. Birth 1994, 21 (1): 4-13.

12. Finlay S, Sandall J: "Someone's rooting for you": continuity, advocacy and streetlevel bureaucracy in UK maternal healthcare. Soc Sci Med 2009, 69(8):1228-1235.

13. Tinkler A, Quinney D: Team midwifery: the influence of the midwife-woman relationship on women's experiences and perceptions of maternity care. $J A d v$ Nurs 1998, 28(1): 30-35.

14. Sandall J, Soltani H, Gates S, Shennan A, Devane D: Midwife-led continuity models versus other models of care for childbearing women. Cochrane Database of Systematic Reviews 2016, 8(CD004667).

15. Page L, Cooke P, Percival P: Providing one-to-one care and enjoying it. The new midwifery: science and sensitivity in practice Edinburgh: Churchill Livingstone 2000( ):123-140.

16. Redshaw M, Martin CR: Validation of perceptions of care adjective checklist. $J$ Eval Clin Pract 2009, 15(2):281-288.

17. Hatem M, Sandall J, Devane D, Soltani H, S. G: Midwife-led versus other models of care for childbearing women. Cochrane Database of Systematic Reviews. 2008, 4:

\section{CD004667.}

18. Terwee CB, Bot SD, de Boer MR, van der Windt DA, Knol DL, Dekker J, Bouter LM, de Vet HC: Quality criteria were proposed for measurement properties of health status questionnaires. J Clin Epidemiol 2007, 60:34-42. 
19. Perriman N, Davis D: Measuring maternal satisfaction with maternity care: A systematic integrative review: What is the most appropriate, reliable and valid tool that can be used to measure maternal satisfaction with continuity of maternity care? Women and Birth 2016, 29:293-299.

20. Wild D, Grove A, Martin M, Eremenco S, McElroy S, Verjee-Lorenz A, Erikson P: Principles of good practice for the translation and cultural adaptation process for patient-reported outcomes (PRO) measures: report of the ISPOR task force for translation and cultural adaptation. Value Health 2005, 8(94-104).

21. Wynd CA, Schmidt B, Schaefer MA: Two quantitative approaches for estimating content validity. West J Nurs Res 2003, 25:508-518.

22. Polit DF, Beck CT: The content validity index: are you sure you know what's being reported? Critique and recommendations. Res Nurs Health 2006, 29:489-497.

23. Netemeyer RG, Bearden WO, Sharma S: Scaling procedures: Issues and applications; 2003.

24. Akgul A, Cevik O: Istatistiksel Analiz Teknikleri [Statistical Analyses Techniques]. Emek Ofset, Ankara 2005.

25. Oner N: Turkiye'de Kullanilan Psikolojik Testlerden Ornekler. Bir Basvuru Kaynagi [Samples from Psychological Tests Used in Turkey. A Reference Source]. 2nd edn. Bogazici Universitesi Yayinevi, Istanbul. 2006.

26. Buyukozturk S: Veri Analizi El Kitabi [Data Analysis Handbook]. Pegem A Yayincilik, Ankara. 2005.

27. Harrington D: Confirmatory Factor Analysis: Oxford university press; 2009. 
28. $\mathrm{Hu} \mathrm{Lt}$, Bentler PM: Cutoff criteria for fit indexes in covariance structure analysis: Conventional criteria versus new alternatives. Structural equation modeling: $a$ multidisciplinary journal 1999, 6(1):1-55.

29. Hair J, Anderson R, Babin B, Black W: Multivariate data analysis: A global perspective (Vol. 7): Pearson Upper Saddle River. In.: NJ; 2010.

30. Waldenström U, Rudman A, Hildingsson I: Intrapartum and postpartum care in Sweden: women's opinions and risk factors for not being satisfied. Acta Obstet Gynecol Scand 2006, 85(551-560).

31. Janssen PA, Dennis CL, Reime B: Development and psychometric testing of the Care in Obstetrics: Measure for Testing Satisfaction (COMFORTS) Scale. Res Nurs Health 2006, 29(51-60).

32. Rudman A, El-Khouri B, Waldenström U: Women's satisfaction with intrapartum care-a pattern approach. $J A d v$ Nurs 2007, 59(474-487).

33. Hollins Martin CJ, V F: The birth satisfaction scale. International Journal of Health Care Quality Assurance 2011, 24(2)(124-35).

34. Hodnett ED: Pain and women's satisfaction with the experience of childbirth: a systematic review. Am J Obstet Gynecol 2002, 186(5):S160-S172.

35. Redshaw M: Women as consumers of maternity care: measuring "satisfaction" or "dissatisfaction"? . Birth 2008, 35(1):73-76.

36. Waldenström U: Why do some women change their opinion about childbirth over time? Birth 2004, 31(2)(102-7).

37. Terwee CB, Bot SD, de Boer MR, van der Windt DA, Knol DL, Dekker J, Bouter LM, de Vet HC: Quality criteria were proposed for measurement properties of health status questionnaires. J Clin Epidemiol 2007, 60(34-42). 
38. Waldenstrom U, Hildingsson I, Ryding E: Antenatal fear of childbirth and its association with subsequent caesarean section and experience of childbirth. $B J O G$ 2006 113(6):638-646.

39. Goodman P, Mackey MC, Tavakoli AS: Factors related to childbirth satisfaction. $J$ Adv Nurs 2004, 46: 212-219.

40. Gamble J, Creedy DK, Teakle B: Women's expectations of maternity services: a community-based survey. Women and Birth 2007, 20(115-120).

41. Martell LK: Postpartum women's perceptions of the hospital environment. Journal of Obstetric, Gynecologic and Neonatal Nursing 2003, 32(478-485).

42. Waldenström U, Hildingsson I, Rubertsson C, Rådestad I: A negative birth experience: prevalence and risk factors in a national sample. Birth 2004 Mar, 31(1):17-27.

43. Sauls DJ: Adolescents' perception of support during labour. Journal of Perinatal Education 2004, 13( 36-42).

44. Mattison CA, Dion ML, Lavis JN, Hutton EK, MG. W: Midwifery and obstetrics: factors influencing mothers' satisfaction with the birth experience. women and Birth 2018, 45(3):322-327.

45. Larkin P, Begley CM, Devane D: 'Not enough people to look after you': an exploration of women's experiences of childbirth in the Republic of Ireland. Midwifery 2012, 28(1):98-105.

46. Salmon P, Drew NC: Multidimensional assesment of women's experience of childbirth: relationship to obstetric procedure, antenatal preperation and obstetric history. . J Psychosom Res 1992, 36(317-327). 
Figures
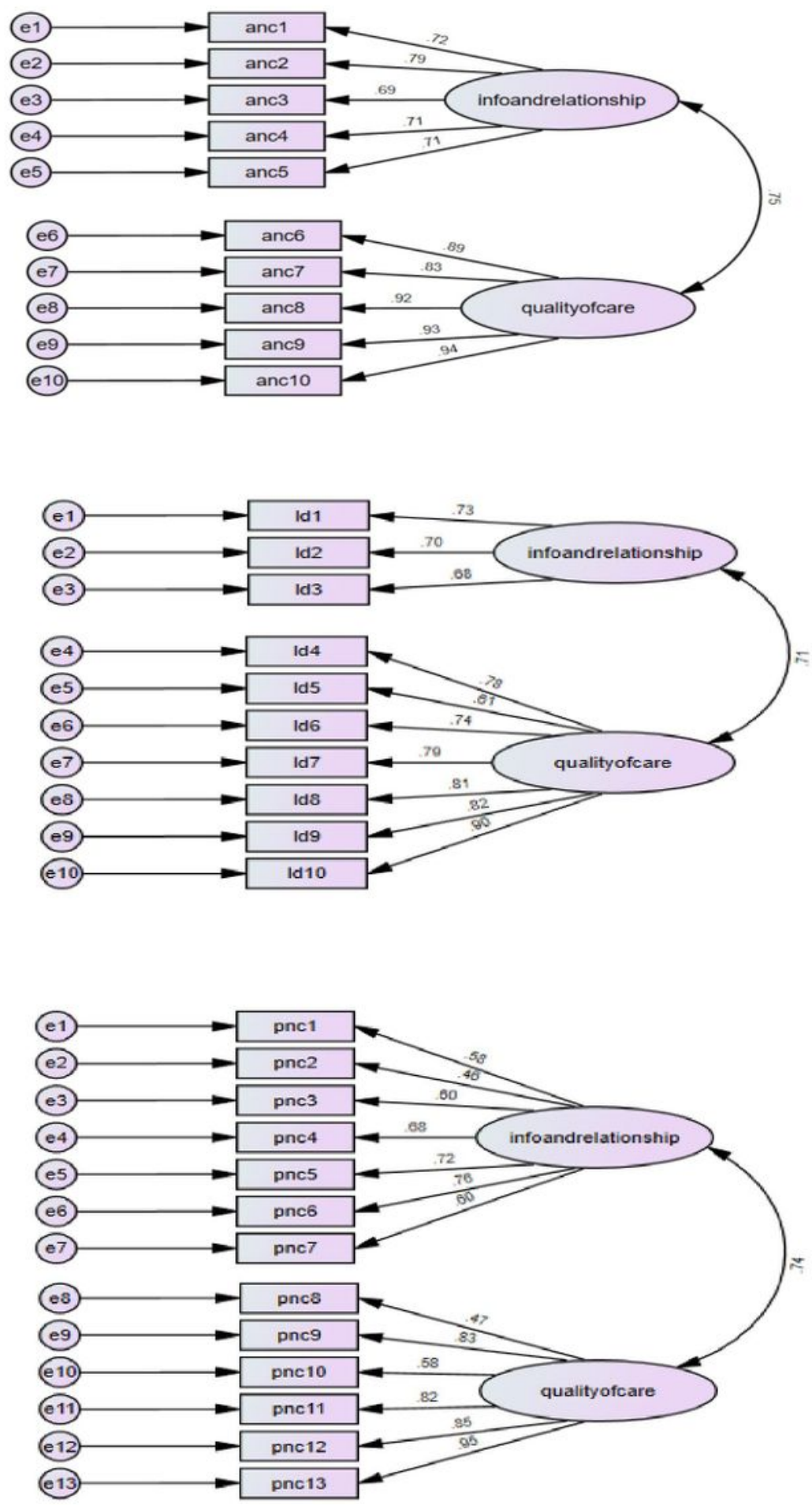

\section{Figure 1}

Confirmatory factor analysis model (Full text annotations of the latent variables for antenatal care, labour and delivery and post-natal care subdomains) 


\section{Supplementary Files}

This is a list of supplementary files associated with this preprint. Click to download.

- Englishversiontool.pdf 